\title{
УДК:632.95:543.544 \\ https://doi.org/10.53040/gppb7.2021.74 \\ РАЗРАБОТКА МЕТОДИКИ ОПРЕДЕЛЕНИЯ ФЛУДИОКСОНИЛА В РАСТЕНИВОДЧЕСКОЙ ПРОДУКЦИИ МЕТОДОМ ГАЗОВОЙ ХРОМАТОГРАФИИ
}

\author{
Арашкович Светлана, Войтка Дмитрий \\ Республиканское научное дочернее унитарное предприятие «Институт защиты расте- \\ ний», Минск, Беларусь, е-mail:bronkamladshaya@mail.ru, d.voitka@tut.by
}

\begin{abstract}
In the publication the methods of fludioxonyl determination in vegetable pea, potato and winter wheat by the method of gas chromatography with the mass-spectrometric detector is presented. The extraction method of soil preparation differs by the simplicity of execution, small use of reagents, expression and provides with the purity of extracts necessary for getting the reproduced quantitative results.
\end{abstract}

Key words: pesticides, residues, fludioxonyl, gas chromatography, methods, plant-growing production.

\section{Введение}

Обеспечение безопасности и качества сельскохозяйственной продукции является одной из основных задач современного общества. Однако на сегодняшний день основная часть продукции сельского хозяйства производится по технологии, предусматривающей достаточно широкое применение химических средств защиты растений.

Обработка семян является одной из важных предпосылок рентабельного производства сельскохозяйственных культур и получения полноценного урожая. Эффективным инструментом в направлении создания благоприятных условий для роста и развития растений являются современные протравители фунгицидного действия.

Сложившаяся фитосанитарная ситуация доказывает, что предпосевное протравливание семян - обязательный прием. Он является наиболее безопасным способом применения пестицидов за счет точечной и точной доставки токсина в зону нанесения вреда. Дополнительным преимуществом системных пестицидов является их относительно низкие нормы внесения на гектар пашни по сравнению с другими способами применения препаратов.

Однако пестициды попадают и накапливаются по ходу биологической цепи, обеспечивающей обмен веществ как между живыми организмами, с одной стороны, и воздухом, водой и почвой - с другой, так и в пищевой цепи, включающей все этапы сельскохозяйственного и промышленного производства продовольственного сырья и пищевых продуктов [1].

Для количественного определения пестицидов используют различные методы. Учитывая высокую токсичность пестицидов, для их мониторинга необходимы специфические и очень чувствительные аналитические методы, позволяющие определять остатки пестицидов и их метаболитов на следовом уровне. Они применяются для определения широкого круга соединений в воздухе, различных водах, почве, растительном материале и продуктах питания.

Важностью контроля за содержанием остаточных количеств пестицидов в пищевых продуктах, сельскохозяйственном сырье, биосредах и объектах природной среды обитания обусловлена разработка новых современных унифицированых методик на основе газовой хроматографии (ГХ) и высокоэффективной жидкостной хроматографии (ВЭЖХ). ГХ чаще применима для обнаружения примесей летучих органических соединений (ЛОС), а ВЭЖХ - для определения высокомолекулярных органических соединений, разлагающихся даже при умеренно высокой температуре $\left(50-100{ }^{\circ} \mathrm{C}\right)[2,3]$.

Флудиоксонил является контактным фунгицидом широкого спектра действия с продолжительной активностью. Высокоэффективен против снежной плесени, твердой головни, гельминтоспориозной и фузароиозной корневых гнилей на зерновых культурах, а также ризоктониоза, склеротиниоза, серой гнили и альтернариоза на винограде, косточковых плодовых, овощных и декоративных культурах [4].

В настоящее время существует достаточное количество методик на различных растительных матрицах по определению остаточных количеств флудиоксонила: «Методические указания по опре- 
делению остаточных количеств флудиоксонила в зерне и масле сои методом высокоэффективной жидкостной хроматографии МУК 4.1.2055-06»; «Определение остаточных количеств флудиоксонила в воде, почве, зеленой массе растений, клубнях картофеля, зерне и соломе хлебных злаков, зерне кукурузы, семенах и масле подсолнечника методом высокоэффективной жидкостной хроматографии МУК 4.1.1148-02»; «Определение остаточных количеств флудиоксонила в семенах и масле рапса, ягодах и соке винограда методом высокоэффективной жидкостной хроматографии МУК 4.1.2332-08»; «Определение остаточных количеств флудиоксонила в томатах методом высокоэффективной жидкостной хроматографии МУК 4.1.2991-12» [2, 3]. Однако они все выполняются методом высокоэффективной жидкостной хроматографии. В связи с отсутствием разработанной методики по определению остаточных количеств действующего вещества флудиоксонила в воде, почве, клубнях картофеля, зеленой массе и зеленом горошке гороха овощного, и зерне пшеницы озимой с помощью газовой хромато-масс-спектрометрии, ее разработка является актуальной.

Поэтому целью исследований была разработка методики определения флудиоксонила в горохе овощном, картофеле и озимой пшенице методом газовой хроматографии.

\section{Материалы и методы}

Разработанная методика основана на определении флудиоксонила газожидкостным методом (ГХ - МС) с масс-селективным детектором после экстракции ацетонитрилом, концентрирования, упаривания на роторном испарителе и очистки на колонке с оксидом алюминия.

\section{Результаты и обсуждения}

Для разработки методики использовали газовый хроматограф с масс-спектрометром GCMSQP2010 Plus компании Shimadzu (Япония). Высокая чувствительность, сверхвысокое хроматографическое разрешение и высокая производительность делает этот метод одним из самых перспективных для определения низких количеств пестицидов в пище и других средах (вода, воздух, почва, биологические среды, растительный материал и др.) [5].

Газовый хромато-масс-спектрометр, снабженным быстрым квадруполем, позволяет работать одновременно в режиме сканирования (Scan) и режиме мониторинга отдельных ионов (SIM) за время прохождения пика. Характеристики, свойственные газовому хроматографу с массспектрометром GCMS-QP2010 Plus компании Shimadzu, позволяют увеличить точность полученных результатов количественного анализа, а, соответственно, и качество результатов анализа.

Количественное определение проводилось методом абсолютной калибровки. Метод специфичен для определения флудиоксонила в воде, почве, клубнях картофеля, зеленой массе и зеленом горошке гороха овощного, и зерне пшеницы озимой.

\section{Выводы}

На основе экспериментальных данных разработана и валидирована методика определения флудиоксонила в горохе овощном, картофеле и озимой пшенице методом газовой хроматографии с масс-спектрометрическим детектированием. Экстракционная методика пробоподготовки отличается простотой исполнения, малым расходом реактивов, экспрессностью и обеспечивает чистоту экстрактов, достаточную для получения воспроизводимых количественных результатов.

\section{Литература}

1. КОБЕЛЕВА, О.В. Пестициды в продуктах питания, произведенных на территории Хабаровского района / О.В. Кобелева // Ученые заметки ТОГУ. - 2013. - №4 (3). - С. 1-8.

2. ДРУГОВ, Ю.С. Контроль безопасности и качества продуктов питания и товаров детского ассортимента: практическое руководство / Ю.С. Другов, А.А. Родин. - М.: БИНОМ. Лаборатория знаний, 2012. - 440 с.

3. Методы определения остаточных количеств пестицидов в растениях, почве и воде: метод. Рекомендации / П.М. Кислушко [и др.]; под ред. П.М. Кислушко; РУП «Ин-т защиты растений». - Минск: Колоград, 2019. - 312 с.

4. Флудиоксонил [Электронный ресурс] / Справочник пестициды. - Режим доступа: http://www.pesticidy.ru/active_substance/fludioxonyl. - Дата доступа: 24.09.2021.

5. Аналитическое лабораторное оборудование Shimadzu [Электронный ресурс] / OОО Лабинтертрейд. Режим доступа: https://abintertrade.by/. - Дата доступа: 15.01.2019. 